\section{Endoscopic closure of a gastropleural fistula}

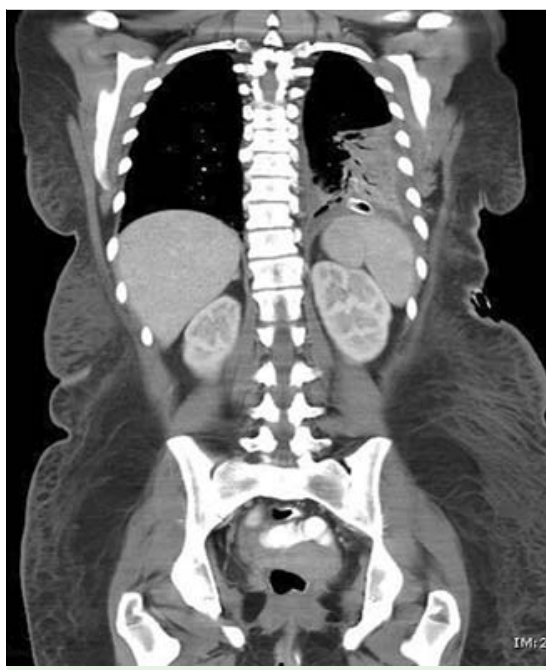

Fig. 1 Computed tomographic scan of the chest showing left lower lobe consolidation and pleural effusion in a 25-year-old woman at 8 weeks after a sleeve gastrectomy for morbid obesity.

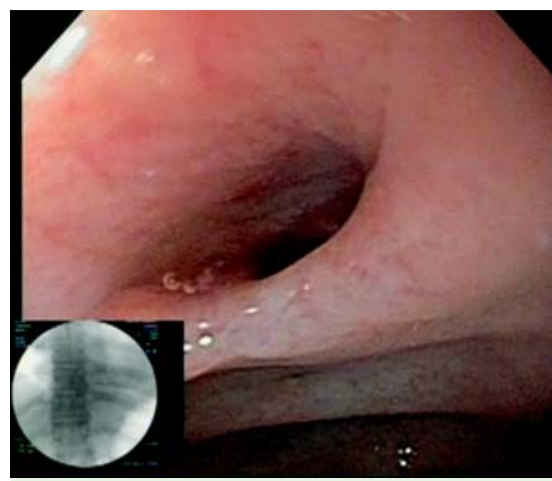

Fig. 2 Gastric opening of the fistula.

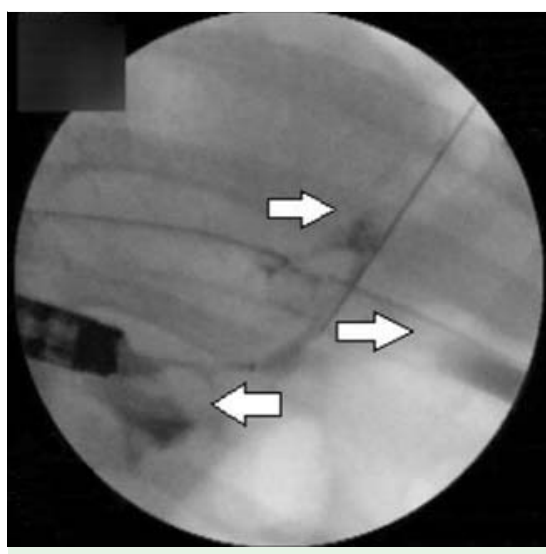

Fig.3 Extravasation of contrast at three different sites (arrows): the stomach, left pleural space, and thoracostomy tube.

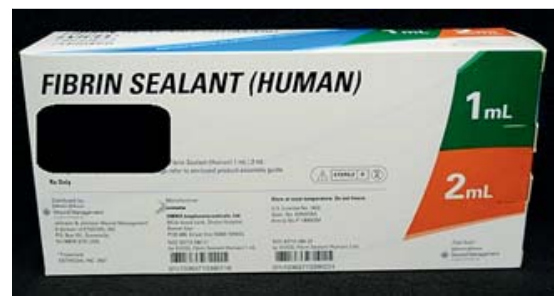

Fig.4 Human fibrin sealant used to close the fistula.

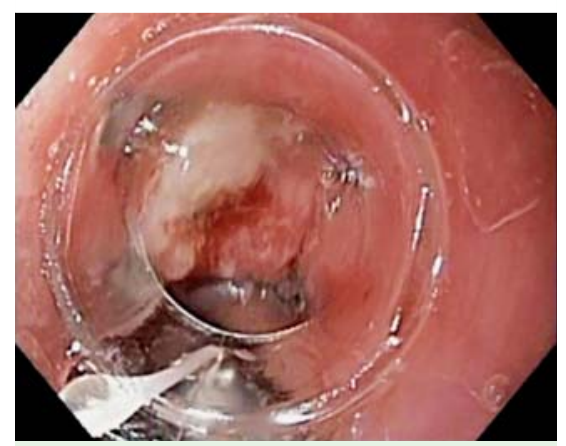

Fig. 5 Over-the-scope clip deployed at the gastric opening of the fistula.

A 25-year-old woman underwent a sleeve gastrectomy for morbid obesity. Over the next 6 weeks, she was hospitalized three times for recurrent pneumonia. She presented to our hospital with the same problem 8 weeks after the surgery. Computed tomography of the chest showed consolidation of the left lower lobe and a left-sided pleural effusion ( $\bullet$ Fig. 1).

A thoracentesis drained purulent fluid; therefore, a thoracostomy tube was placed. Given the abrupt onset of the recurrent pneumonia after the surgery, a fistula was suspected. An upper gastrointestinal series showed extravasation of contrast from the stomach into the left hemithorax, so that a diagnosis of gastropleural fistula was established.

At endoscopy, the gastric opening of the fistula was identified ( $\bullet$ Fig.2). Under fluoroscopic guidance, a 0.35 -wire was advanced into the left pleural space. After the injection of contrast, extravasation was observed at the stomach, pleural

\section{Video 1}

Endoscopic closure of a gastropleural fistula. space, and thoracostomy tube ( $\bullet$ Fig. 3 ). A cytology brush was used to abrade the tract and facilitate closure. The gastric opening was then fulgurated with argon plasma cautery, and the tract was sealed with human fibrin ( $\bullet$ Fig.4). The fibrin was injected through a triple-lumen ramp, starting at the pleural space and ending at the gastric opening. The procedure was finalized by deploying an overthe-scope clip at the gastric opening $(\bullet$ Fig.5). The patient was discharged two days later and has remained asymptomatic since the procedure, which is shown in Video 1.

Gastropleural fistulas are infrequent. The few reported cases suggest such underlying causes as malignancy, trauma, and complications of abdominal and thoracic surgery $[1,2]$. Recently, bariatric surgery has been associated with gastrobronchial fistula, which is a slightly different entity but with identical pathophysiology [3]. The treatment of gastropleural fistula to date has been strictly surgical $[4,5]$. We report a novel endoscopic approach in which a combination of established endoscopic techniques and recent accessories was used for the successful treatment of this rare condition.

\section{Endoscopy_UCTN_Code_TTT_1AO_2AI}

Competing interests: None

\section{Antonio Mendoza Ladd ${ }^{1}$, Ihsan Al-} Bayati $^{1}$, Paresh Shah ${ }^{2}$, Gregory Haber ${ }^{3}$

${ }^{1}$ Division of Gastroenterology, Department of Medicine, Paul L. Foster School of Medicine, Texas Tech University Health Sciences Center, El Paso, Texas, USA 2 Division of General Surgery, New York University Langone Medical Center, New York, New York, USA

${ }^{3}$ Division of Gastroenterology, Department of Medicine, Lenox Hill Hospital, New York, New York, USA

\section{References}

1 O'Keefe P, Goldstraw P. Gastropleural fistula following pulmonary resection. Thorax 1993; 12: $1278-1279$

2 Takeda S, Funaki S, Yumiba T et al. Gastropleural fistula due to gastric perforation after lobectomy for lung cancer. Interact Cardiovasc Thorac Surg 2005; 5: 420 - 422

3 Campos J, Pereira E, Evangelista L et al. Gastrobronchial fistula after sleeve gastrectomy and gastric bypass: endoscopic management and prevention. Obes Surg 2011; 10: $1520-1529$ 
4 Virlos I, Asimakopoulos G, Forrester-Wood C. Gastropleural fistula originating from the lesser curve: a recognised complication, an uncommon pathway of communication. Thorac Cardiovasc Surg 2001; 5: 308 - 309

5 Mehran A, Ukleja A, Szomstein $S$ et al. Laparoscopic partial gastrectomy for the treatment of gastropleural fistula. JSLS 2005; $2: 213-215$
Bibliography

Dol http://dx.doi.org/

10.1055/s-0034-1391357

Endoscopy 2015; 47: E131-E132

(c) Georg Thieme Verlag KG

Stuttgart · New York

ISSN 0013-726X
Corresponding author

Antonio Mendoza Ladd, MD

Division of Gastroenterology

Department of Medicine

Paul L. Foster School of Medicine

Texas Tech University Health Sciences Center 4800 Alberta Avenue

El Paso, TX 79905

USA

Fax: 1-915-215-5289

dr_ladd25@yahoo.com 